JOURNAL OF

APPLIED

CRYSTALLOGRAPHY

ISSN 1600-5767

\section{The Beauty of Chemistry: Art, Wonder, and Science. By Philip Ball. Photographs by Wenting Zhu and Yan Liang. MIT Press, 2021. Pp. 308. Hardback price USD 49.45. ISBN 978-0262044417.}

\author{
John R. Helliwell*
}

Department of Chemistry, University of Manchester, Manchester M13 9PL, United Kingdom. *Correspondence e-mail: john.helliwell@manchester.ac.uk

Having been commissioned to write this book review, by coincidence I cycled past the University of Manchester Whitworth Art Gallery whose current headline to attract visitors is 'Making art useful since 1889'. Juxtaposing 'Useful art' and 'beautiful chemistry' seemed to require a word rearrangement to 'beautiful art' and 'useful chemistry'. The issues are complex, though: some art is designed to shock and some science does not even seek to be useful, in the first instance, but is designed to answer a question. So, in deciding how to approach this book I pre-decided that it is maybe best regarded as the portion of chemistry that is beautiful. For instance, Napoleon's soldiers stuck in the Russian winter of 1812 I doubt very much would have regarded the tin buttons on their coats, smashed by the cold, as examples of beautiful chemistry of the polymorphs of tin. On to my starting thoughts of one of the authors, Philip Ball: I recalled the opening ceremony of the International Year of Crystallography held in Paris in January 2014 when he superbly, to my mind, chaired a panel discussion of young crystallographers.

On to the book. The opening Introduction: the beauty of chemistry describes the authors' sense of wonder of chemistry. In particular, the opening sentence deals with the point I raised above, saying 'chemistry is a confluence of the practical and the sublime'.

Chapter 1 is entitled Elemental: the allure of chemistry, in which the focus is on bubbles produced in various chemical reactions. These include carbon dioxide in fizzy drinks such as champagne but also occurring in electrolysis. The less than beautiful impact of $\mathrm{CO}_{2}$ on climate change and on the acidification of the oceans and its impact on coral is discussed.

Chapter 2 is Orderly: the charm of crystals. This chapter has beautiful pictures. Sodium chloride is featured, as is copper sulfate. There is an apt description of close packing but (page 48) the interpenetrating layout of ions in sodium chloride is put in an appendix. Several of the excellent crystal photographs are in polarized light, but it is not explained why; this may confuse inexperienced readers, who are probably the target audience of this book. Actually, who is the target audience for this book? Page 60 carries a sketch of X-ray crystal structure analysis. Page 63 makes the statement (three times) that the DNA double helix was discovered via a crystal structure, when it was a fibre X-ray diffraction based structure. Page 64 states that 'crystal growing is a black art'. Actually I would assert that we have long been moving ahead of that perception and that there is a steadily growing, systematic, knowledge of crystallization science. Anyway the chapter moves on to delightful descriptions of minerals and even crystallized nitrogen on the dwarf planet Pluto. Page 69 has the delightful sentence 'When we watch crystals grow in the lab we are seeing one of nature's universal acts of creation; atoms given collective form, an expression of nature's geometric dreams.'

Chapter 3 is Insoluble: the power of precipitation. At page 84 we get a big clue on who the target audience for the book is: '(Beware: science is full of descriptions masquerading as explanations.)'. So, the readership imagined is not practising scientists, who would happily label an explanation in science as phenomenological, or alternatively qualitative or quantitative. I checked the whole book and the publisher's website and the target readership for the book is not stated. At page 89 is a lucid description of water and hydrogen bonding as well as the electron lone pairs on the oxygen. This is a hard topic to explain to a non-scientist, and it is nicely done here. But next is an unforgivable sin in my opinion on page 108, with the topic of proteins in extreme environments strangely juxtaposed with pictures of the unrelated precipitation of iron, nickel and copper 
hydroxides. There are then widely meandering descriptions under the precipitation chapter title, but actually all of them engage one's interest very well.

Chapter 4 is Exuberant: the delight of dendritic growth. The chapter starts with a tribute to the beauty of snowflakes, 'the flowers of snow'. Here are posed two very good questions 'why the needles?' and 'what makes a tip sprout branches and at a particular angle?'. The chapter is again a meander but quite pleasing. Oddly, the many delightful pictures in the chapter are of inorganic dendrites but no snowflakes; maybe it is assumed that we all know those.

Chater 5 is Incendiary: the fascination of flames. This is indeed a very fascinating topic and close to everyday life connections: a really good choice. The explanations bring in Michael Faraday, Count Rumford and John Dalton, as well as the ancient Greeks. I especially liked the sentence (page 174) 'In chemical reactions atoms are redistributed into new unions.' There is then the assertion (page 176) 'the candle: the driving force of the industrial age', which strikes me as rather odd. Rather I would say that water wheels installed at fastflowing rivers emanating off the Pennine hills drove the looms in the cotton mills around Manchester and hence the Industrial Revolution. But the book does have a point that a cigarette lighter (photograph on page 185) creates a flame not for light but for heat. (NB I later found mention of water wheels for power on page 321.) Page 190 describes the carbon fragments generated in a candle flame and into $\mathrm{C}_{60}$. The closing pages of text in this chapter focus on the distinctive flame colours of the elements, sodium yellow of street lights and so on, which is really good as readers can see those directly in their daily life.

Chapter 6 is Galvanizing: the enchantment of electrochemistry. In this chapter the topics are so diverse, that - given the style of the whole book with no diagrams, only colour swirls and pictures - the inexperienced reader will have little to no idea of what is described. There are moments of clarity such as provided by the simple example of the Voltaic (battery) pile. I think this chapter needs simplifying or doing in a different format beyond swirly pictures, no matter how beautiful.

Chapter 7 is Chromatic: the curiosity of colour changes in plants. The chapter opens with multiple mistreatments of flowers. The impact of sodium hydroxide and its six pages of colour photographs seems a strange place to start this chapter. There follows the impact of bleach and hydrochloric acid along with further colour pictures of the resulting ex-flower petals. Not much beauty in chemistry here, I think. At page 244 we get back on track with the natural colouring agents of chlorophyll, carotenoids and anthocyanin. But then yet more pages of chemicals attacking leaves. After this the chapter resuscitates itself again with descriptions of the impact of different soils on the colour of hydrangeas in our gardens, as well as the manipulation of the colours of roses by horticulturalists: but no pictures of these pleasing varieties.

Chapter 8 is Calescent: the helpfulness of heat. The opening sentence is a delight 'We see such a small slice of reality that it is a wonder we manage in the world at all.' Also the picture of a drop of sulfuric acid in water is amazing: not watched by eye, which discerns nothing, but through a thermal imaging camera showing efflorescence and a burst of heat. There then follows a wide variety of fascinating examples, with the chemistry details sparklingly explained. Of course, this chapter, being preoccupied with heat, eventually has to explain enthalpy and entropy, and the book makes a very good attempt at these challenging concepts. Each chapter concludes with a helpful further reading list and usually a quote from a well known scientist. The quote at the end of Chapter 8 is from the 1981 Nobel Prize winning chemist Roald Hoffmann, which is especially vivid and well chosen.

Chapter 9 is Organic: the contortions of chemical gardens. This chapter is again beautifully illustrated with numerous examples of various coloured chemical gardens. The chapter scrutinizes, and supports, the many previous notions that chemical gardens may help explain the origin of life, such as around ocean hydrothermal vents. The warm vents and the combination of silicate 'membrane structures' and a variety of organic and inorganic chemicals form a 'chemical garden' basis for life to begin. The further reading list of page 324 is again enticing, but I would have liked to have seen on the list J. D. Bernal's book The Origin of Life.

Chapter 10 is Creative: the profusion of patterns. This introduces the reader to the self-organizing chemical patterning ideas known as Turing structures. This leads on to the fascinating Belousov-Zhabotinsky oscillating chemical reaction in solution, switching between red and blue. Quite possibly the most appealing to crystallographers of all the photographs in the book is that on page 343 , showing the Liesegang rings when 'a central droplet of silver nitrate diffuses into a layer of gel containing potassium dichromate in a Petri dish'. This is a pentagonal arrangement of black spots with rings around each one. This truly arouses one's deep interest and wonder. This example also concerns the mathematics of diffusion and time-dependent differential equations, although this is not explored. (A weakness of the book is the absence of mathematics, which is a pity but no doubt intended to spare the general reader; is that a good idea though?)

At page 355 is the Postscript: art, wonder and science. At page 359 the acknowledgments include 'Science Communication in China and the Chinese Chemical Society, who supported the Envisioning Chemistry project and from which the beautiful images came from Yan Liang and Wenting Zhu'. At page 361 is an appendix, Molecules and Structures, with a few words on scanning tunnelling microscopy and X-ray crystallography as well as an explanation of molecular graphics and photographs of various inorganic, organic and biological 3D structures. There is a Glossary of terms which is a useful anchor for the more determined readers of the book. The sources of the inspirational quotations throughout the book are acknowledged in more detail on pages 379-380. There is no subject index.

In summary, with the spectacular image at page 343 alone, and many others in this book, we can acknowledge that the title of the whole book The Beauty of Chemistry is successfully demonstrated. Also, with just a few exceptions noted above, I 


\section{book reviews}

think the narrative, albeit meandering, shows a deep and broad knowledge and engages the reader well. The book also successfully combines chemistry with interesting excursions into physics, mineralogy and biology. I think this book will engage the general reader during, for example, long winter evenings.

Incidentally, those readers of this book review still wondering why the University of Manchester Whitworth Art Gallery is advertising itself as 'Making art useful since 1889', the answer is textiles. This is a tribute to the Industrial
Revolution, seeded here, where the initiatives of science were successfully combined with colours and patterns to achieve attractive and yet durable clothing. I encourage you to visit Manchester and this lovely art gallery. And not so far away is the Manchester Museum of Science and Industry, which also features beautiful textiles as well as heavy machinery from the mills. Utility and beauty can be combined.

Finally, a very nice explanatory five-minute video by the author is also available at https://www.youtube.com/watch?v= 9tFnJYpiKag, which I think is well worth watching. 